\title{
Cervical Metaplasia
}

National Cancer Institute

\section{Source}

National Cancer Institute. Cervical Metaplasia. NCI Thesaurus. Code C4056.

Metaplastic changes in the cervical glandular or squamous epithelium. 